\title{
HISTOPATHOLOGY OF DIABETIC RETINOPATHY IN MAN
}

\author{
ALEC GARNER \\ London
}

\begin{abstract}
SUMMARY
The retinal changes associated with diabetes mellitus are a consequence of the systemic microangiopathy with modifications related to the intraocular environment. The vascular disorders underlying background retinopathy are arteriolar hyalinosis (which together with abnormalities in the circulating blood can give rise to focal capillary closure), venular dilatation, and capillaropathy in the form of pericyte degeneration, basement membrane thickening and microaneurysm formation. Retinal complications consist of plasma exudation and punctate haemorrhages. Maculopathy is due to cystoid oedema. Increasing closure of capillaries is linked with cotton-wool spots and intraretinal microvascular anomalies, the former reflecting a consequence and the latter a response to increased ischaemia. Vascular proliferation in front of the retina originates from venules close to areas of ischaemia; the endothelium may be fenestrated initially and fibrosis may accompany the new vessels.
\end{abstract}

The retinal changes associated with diabetes mellitus result from the interaction of the microangiopathy characteristic of the diabetic process in general with local factors determined by peculiarities of the ocular environment. In this brief survey I will attempt to summarise the various morphological features of diabetic retinopathy and relate them to their clinical context. Some of the interrelationships are indicated in Fig. 1.

\section{HISTOLOGICAL CHANGES ASSOCIATED WITH BACKGROUND RETINOPATHY}

\section{Vascular Changes}

Pericyte Degeneration. An early and seemingly invariable feature is degeneration of the retinal capillary pericytes. Transmission electron microscopy indicates that there is cell necrosis, and in enzyme digest preparations this is correlated with a lack of nuclear staining in periodic acidSchiff (PAS)-treated sections ('ghost outlines') ${ }^{1}$ and

Correspondence to: Professor A. Garner, Department of Pathology, Institute of Ophthalmology, Bath Street, London EC1V 9EL, UK. nuclear eosinophilia in haematoxylin and eosin preparations. ${ }^{2}$ Although it is possible that comparable pericyte degeneration occurs in the capillaries of other tissues, nowhere does it appear to reach the level observed in the retina, not even in the optic nerve. ${ }^{3}$ This suggests that local factors are important in its pathogenesis and it is to be noted that, while hyperglycaemia with undue utilisation of the polyol pathway of glucose metabolism has been implicated ${ }^{4}{ }^{4}$ selective loss of pericytes can also occasionally develop in non-diabetic retinal disorders. ${ }^{5}$

Microaneurysms, Again, while capillary aneurysms are not peculiar to the retina, having been described in the conjunctival and cardiac muscle ${ }^{6}$ of diabetic subjects, they are a particularly common finding. From a morphological standpoint two types can be recognised: those developing as saccular distensions of the vessel wall and those originating as kinks or loops. ${ }^{7}$

Saccular aneurysms may be presumed to evolve at weak points in the capillary wall and to be abetted by increases in intraluminal pressure. Reduced structural strength if not contractile activity secondary to pericyte loss could be a factor, ${ }^{1.8}$ but the lack of precise correlation suggests that this alone is not a sufficient cause. A more recent attempt to implicate the pericyte in microaneurysm formation has centred on the effect that withdrawal of the inhibitory influence of this cell might have on endothelial cell proliferation: $:^{9}$ the suggestion is that this could allow limited 'budding' of the capillary. Increased perfusion pressure secondary to vasodilatation in the face of tissue hypoxia and loss of capillary tone can be invoked, as can pressure increase as a result of hyperviscosity and consequent obstructed outflow.

Retinal microaneurysms are not peculiar to diabetes, but the loop type is uncommon in non-diabetic disorders. Aneurysms of this sort appear to develop through the partial fusion of contiguous arms of a kinked segment of a capillary, ${ }^{7}$ resulting possibly from localised lengthening and increased calibre due to endothelial cell hyperplasia. A tendency for the loops to point towards foci of capillary closure can be interpreted as evidence of a limited neovas- 


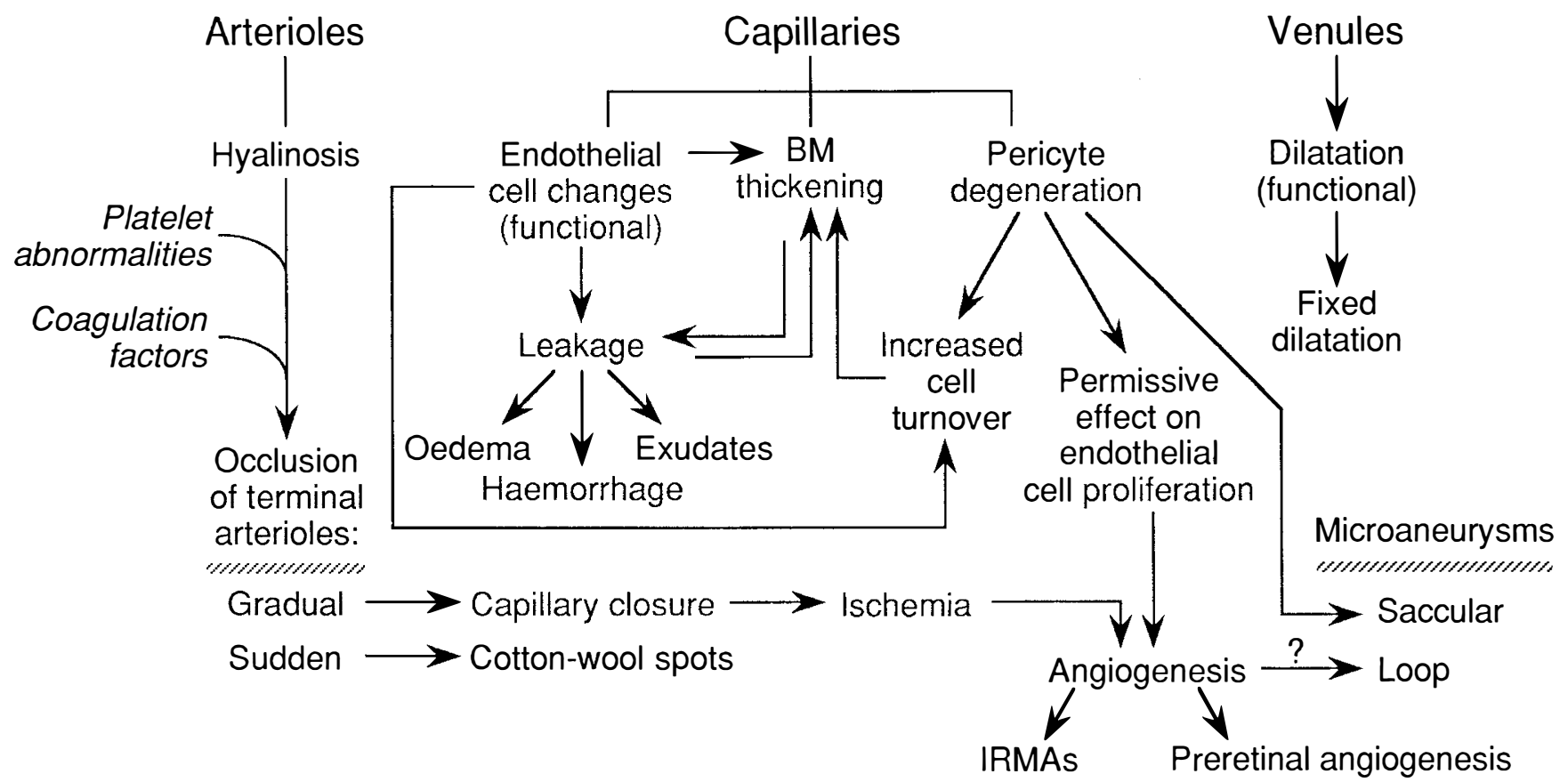

Fig. 1. Postulated sequence of events underlying the tissue changes in diabetic retinopathy. BM, basement membrane; IRMA, intraretinal microvascular anomaly.

cular response to factors diffusing from the ischaemic tissue.

Basement Membrane Thickening. Retinal capillaries resemble their counterparts in other tissues in showing basement membrane thickening ${ }^{10}$ and, whilst increased synthesis with reduced turnover ${ }^{11}$ is likely to be the major factor, gradual incorporation of plasma residues may be a further consideration. An increase in perivascular reticulin is also usual. ${ }^{12}$ Occasionally the thickened membrane can also be seen to be laminated and, in the context of the renal glomerulus, this has been attributed to reduced turnover such that the synthetic activity accompanying cell renewal is not balanced by parallel degradation as the cells degenerate. ${ }^{13,14}$ Alongside the increase in thickness is a lower proteoglycan content which has the effect of reducing the electrical charge barrier function and increasing membrane permeability. 11,15

Arteriolar Hyalinosis. Hyaline thickening of the arteriolar wall occurring as a function of ageing and mild hypertension is accentuated in diabetes. In part it represents replacement of the smooth muscle elements by fibrous tissue, but insidious permeation of the wall by plasmaderived constituents is also important. As such the enhanced incidence of hyalinosis is likely to be a manifestation of the increased endothelial cell permeability associated with diabetes. Reduced calibre of the terminal retinal arterioles consequent to the mural thickening may contribute to the risk of occlusion and capillary closure downstream.

Venular Dilatation and Tortuosity. Some patients display a mild increase in venular calibre ${ }^{16}$ which, in that it is initially open to reversal in response to normoglycaemia, ${ }^{17}$ appears to be a functional change. With time it may become permanent as sclerosis supervenes.

\section{Retinal Complications}

Exudates. Retinal hard exudates consist of inspissated plasma. As such they represent leakage from the circulation at a level that probably requires a degree of structural damage to the vascular endothelium. Capillaries, those with microaneurysmal dilatation in particular, are the principal source. Initially fluid, the exuded plasma seeps into the outer plexiform layer where it collects. From the prevalence of exudates at this level it can be inferred that the inter-photoreceptor and Müller cell junctional complexes present an obstacle to the further movement of molecules the size of lipids and proteins whereas water passes towards the choroid unimpeded. In this way the exudate becomes progressively inspissated to leave semisolid residues qualifying for the description hard or waxy.

Haemorrhages. Intraretinal bleeding in diabetes is usually described as punctate and is chiefly seen around microaneurysms.

\section{HISTOLOGICAL CHANGES ASSOCIATED WITH MACULOPATHY}

\section{Oedema}

Sight-threatening changes at the macula, such as are most commonly seen in type 2 (non-insulin-dependent) diabetes, are presumed to be a consequence of tissue oedema. Histological examination reveals cystoid spaces located principally in the outer plexiform (Henle's) layer, sometimes with additional involvement of the inner retinal layers. ${ }^{18}$ Transudation from perifoveal blood vessels may be a contributory factor but an ultrastructural study suggests that the primary change is intracellular, Müller cells in particular accumulating fluid which only later 
spills into the extracellular compartment. ${ }^{19}$ Among the various attempts to account for the maculopathy ischaemia has probably attracted most support, ${ }^{18}$ although attention has also been drawn to the potential role of the pigment epithelium ${ }^{20}$ which, contrary to earlier understanding, is now known to be an insulin-dependent cell type, ${ }^{21}$ and to the vitreous. ${ }^{22}$

\section{HISTOLOGICAL CHANGES ASSOCIATED WITH PREPROLIFERATIVE RETINOPATHY}

\section{Vascular Changes}

Capillary Closure. Foci of unperfused capillaries appear in conjunction with background retinopathy, but withincreased duration of the diabetic state they tend to increase in size and number. Thrombotic occlusion of the feeding arteriole is the most logical explanation, although direct confirmation of this is sparse. The non-functioning capillaries are reduced to acellular tubes of basement membrane. ${ }^{1,2}$

\section{Retinal Complications}

Cotton-wool Spots. Minor foci of capillary closure may have little or no functional consequence, but where the foci increase sufficiently they incur a danger of cottonwool spot formation. Cotton-wool spots can be produced experimentally by artificially obstructing blood flow at the level of the precapillary arteriole ${ }^{23}$ and represent a response to acute ischaemia. Histologically they are seen as aggregates of cytoid bodies in the nerve fibre layer of the retina, each cytoid body comprising the bulbous swelling at the end of a disrupted axon. ${ }^{24,25}$ Interference with axoplasmic flow $^{26}$ supplemented by intracellular oedema $^{19}$ appears to be the basis for the swelling.

Intraretinal Vascular Anomalies. Dilated, elongated and frequently tortuous capillary loops are sometimes observed invading areas of capillary closure. Vessels of this type may be either remodelled versions of existing capillaries or entirely new structures, ${ }^{27}$ and it is probably because of the uncertainty as to their origin that the term intraretinal microvascular anomaly (IRMA) has evolved. Initially at least they are dilated relative to the normal capillaries, but leakage, as judged by fluorescein angiography, is minimal. ${ }^{28}$

\section{HISTOLOGICAL CHANGES ASSOCIATED WITH PROLIFERATIVE RETINOPATHY}

\section{Vascular Changes}

Neovascularisation. The vessels responsible for the proliferative phase of diabetic retinopathy arise from the venous side of the circulation and penetrate the inner limiting lamina of the retina before fanning out along its surface. They are commonly associated with reduced or absent perfusion of the underlying retina and there is circumstantial evidence to blame the consequent tissue hypoxia for the angiogenic stimulus. ${ }^{29}$ The new vessels arise in a conventional manner through a budding process and for a time are devoid of pericytes..$^{30,31}$ Leakage and microscopic haemorrhage can occur before the immature capillaries develop tight junctions. ${ }^{32}$ Fenestrae have been described in the cytoplasm of the preretinal capillaries ${ }^{33-36}$ but this may be another transient phenomenon. Eventually the vessels can acquire a mantle of fibrous tissue and, rarely, spontaneous regression to leave a cluster of a cellular channels may occur.

\section{Retinal Complications}

Vitreous Haemorrhage. Intravitreal bleeding can ensue because of damage to new vessels that have invaded the vitreous body by growing along condensations of the vitreal collagen.

Retinal Detachment. Detachment occurs because of traction exerted by the adventitial cells surrounding the proliferating vessels. Mostly these are fibroblasts although glial tissue, particularly Müller cells, ${ }^{37}$ and even cells derived from the retinal pigment epithelium, ${ }^{35}$ may add to the overall effect.

Key words: Diabetes, Histology, Retina.

\section{REFERENCES}

1. Cogan DG, Toussaint D, Kuwabara T. Retinal vascular patterns. IV. Diabetic retinopathy. Arch Ophthalmol 1961;66:366-78.

2. Ashton N. Studies of the retinal capillaries in relation to diabetic and other retinopathies. $\mathrm{Br} \mathrm{J}$ Ophthalmol 1963;47:521-38

3. Addison DJ, Garner A, Ashton N. Degeneration of intramural pericytes in diabetic retinopathy. BMJ 1970;1:264-6.

4. Kinoshita JH. Aldose reductase in the diabetic eye. XLIII. Edward Jackson Memorial Lecture. Am J Ophthalmol 1986; 102:685-92.

5. Ashton N. Diabetic retinopathy: some current concepts. In: Proceedings of the international symposium on fluorescein angiography, Albi 1969. Basel: Karger, 1971:334-45.

6. Factor SM, Okun EM, Minase T. Capillary microaneurysms in the human diabetic heart. N Engl J Med 1980;302:384-8.

7. Ashton N. Diabetic micro-angiopathy. Adv Ophthalmol 1958;8 (Bibl Ophthalmol Fasc):1-84.

8. Yanoff M. Ocular pathology of diabetes mellitus. Am J Ophthalmol 1969;67:21-38.

9. Frank RN. On the pathogenesis of diabetic retinopathy. Ophthalmology 1991;98:586-93.

10. Ashton N. Vascular basement membrane changes in diabetic retinopathy. Br J Ophthalmol 1974;58:344-66.

11. Abrahamson DR. Recent studies on the structure and pathology of basement membranes. J Pathol 1986;149:257-78.

12. Ashton N, Tripathi RC. Perivascular and intervascular reticular fibres of the retina. Am J Ophthalmol 1975;80:337-59.

13. Vracko R. Basal lamina layering in diabetes mellitus: evidence for accelerated rate of cell death and cell regeneration. Diabetes 1974;23:94-104.

14. Furness PN, Turner DR, Cotton RE. Basement membrane charge in human glomerular disease. J Pathol 1986;150:267-78.

15. Sterberg M, Cohen-Forterre L, Peyroux J. Connective tissue in diabetes mellitus: biochemical alterations of the intercellular matrix with special reference to proteoglycans, collagens and basement membranes. Diabet Metab 1985; 11:27-50.

16. Skovberg F, Nielsen AV, Lauritzen E, Hartkopp O. Diameters of the retinal vessels in diabetic and normal subjects. Diabetes 1969; 18:292-8. 
17. Larsen HW. Diabetic retinopathy. Acta Ophthalmol 1960;60 Suppl:1-89.

18. Tso MOM. Pathological study of cystoid macular edema. Trans Ophthalmol Soc UK 1980;100:408-13.

19. Fine BS, Brucker AJ. Macular edema and cystoid macular edema. Am J Ophthalmol 1981;92:466-81.

20. Bresnick GH. Diabetic maculopathy: a clinical review highlighting diffuse macular edema. Ophthalmology 1983;90: 1301-17.

21. Micelli MC, Newsome DA. Cultured retinal pigment epithelial cells from donors with type I diabetes show an altered insulin response. Invest Ophthalmol Vis Sci 1991;32:2847-53.

22. Nasrallah FP, Jalkh AH, Coppenhollre F van, Kado M, Trempe CL, McMeel JW, Schepens CL. The role of the vitreous in diabetic macular edema. Ophthalmology 1988;95:1335-39.

23. Ashton N, Dollery CT, Henkind P, Hill DW, Paterson JW, Ramalho PS, Shakib M. Focal retinal ischaemia: ophthalmoscopic, circulatory and ultrastructural changes. $\mathrm{Br} \mathrm{J}$ Ophthalmol 1966;50:281-384.

24. Wolter JR. Pathology of a cotton-wool spot. Am J Ophthalmol 1959;48:473-85.

25. Ashton N, Harry J. The pathology of cotton-wool spots and cytoid bodies in hypertensive retinopathy and other diseases. Trans Ophthalmol Soc UK 1963;83:91-114.

26. McLeod D, Marshall J, Kohner EM, Bird AC. The role of axoplasmic transport in the pathogenesis of retinal cottonwool spots. Br J Ophthalmol 1977;61:177-91.
27. Mohan R, Kohner EM. Retinal revascularisation in diabetic retinopathy. Br J Ophthalmol 1986;70:114-7.

28. Archer DB. Neovascularisation of the retina. Trans Ophthalmol Soc UK 1976;96:471-93.

29. Garner A. Ocular angiogenesis. Int Rev Exp Pathol 1986;28:249-306.

30. Cogan DG, Kuwabara T. Capillary shunts in the pathogenesis of diabetic retinopathy. Diabetes 1963;12:293-300.

31. Taniguchi Y, Sanashima M, Fukiyama M. Electron microscopic study of newly formed blood vessels in diabetic retinopathy. Acta Soc Ophthalmol Jpn 1973;77:1383-93.

32. Miller H, Miller B, Zonis S, Nir I. Diabetic neovascularisation: permeability and ultrastructure. Invest Ophthalmol Vis Sci 1984;25:1338-42.

33. Taniguchi Y. Ultrastructure of newly formed blood vessels in diabetic retinopathy. Jpn J Ophthalmol 1976;20:19-31.

34. Wallow IHL, Geldner PS. Endothelial fenestrae in proliferative diabetic retinopathy. Invest Ophthalmol Vis Sci 1980;19:1176-83.

35. Hamilton CW, Chandler D, Klintworth GK, Machemer R. A transmission and scanning electron microscopic study of surgically excised preretinal membrane proliferations in diabetes mellitus. Am J Ophthalmol 1982;94:473-88.

36. Williams JM, de Juan E, Machemer R. Ultrastructural characteristics of new vessels in proliferative diabetic retinopathy. Am J Ophthalmol 1988;105:491-9.

37. Nork TM, Wallow IHL, Kramer SJ, Anderson G. Müller cell involvement in proliferative diabetic retinopathy. Arch Ophthalmol 1987;105:1424-9. 